$\mathbb{P}$ periodica polytechnica

\author{
Civil Engineering \\ 58/4 (2014) 319 333 \\ doi: $10.3311 /$ PPci.7416 \\ http://periodicapolytechnica.org/ci \\ Creative Commons Attribution (1) \\ RESEARCH ARTICLE
}

\section{Determination of optimal pipe diameters for radial fixed-track district heating networks}

\author{
László Garbai / Andor Jasper / Jenö Kontra
}

Received 2014-03-13, revised 2014-05-07, accepted 2014-07-07

\begin{abstract}
This paper presents the basics of Bellmann's dynamic programming, to be applied for radial fixed-track district heating networks. A decision-making model thereof is produced, and Garbai's scaling method [1] is applied in a new, narrower interval by using a tagging method well-known from computer science. Thereby the result yielded coincides with that of the previous method, but the number of calculations to be performed is reduced considerably.
\end{abstract}

\section{Keywords}

district heating $\cdot$ optimal pipe diameters $\cdot$ dynamic programing $\cdot$ optimization

\section{László Garbai}

Department of Building Service and Process Engineering, Budapest University of Technology and Economics, Múegyetem rkp. 3, H-1111 Budapest, Hungary

\section{Andor Jasper}

Department of Building Service and Process Engineering, Budapest University of Technology and Economics, Múegyetem rkp. 3, H-1111 Budapest, Hungary e-mail: jasper@epgep.bme.hu

\section{Jenő Kontra}

Department of Building Energetics and Building Service Engineering, Budapest University of Technology and Economics, Múegyetem rkp. 3, H-1111 Budapest, Hungary

\section{Introduction}

Public utilities in network systems perform very important tasks in the life of settlements. District heating systems represent a most sophisticated technology among public utility networks. They are highly asset-intensive, their development and operation are costly; at the same time, they play a major role in energetics as they provide space and opportunities for combined heat and power generation. 650 thousand apartments, most of them built by using a system building technology in the course of the past few decades, are supplied with district heating. The economic optimization of the construction and operation of district heating networks can make district heating much cheaper. Construction optimization refers to the specification of optimal pipe diameters.

Specification of optimal pipe diameters for district heating systems involves the selection of a conduit diameter for each section of the district heating system whereby the annual proportion of the investment cost of the network, the annual direct cost of operation, as well as the aggregate cost of hot water circulation and heat loss are minimized.

An efficient solution for this problem, effective from the engineering point of view and of substantial practical value, is still missing.

This problem arose in the $1960 \mathrm{~s}$ and $1970 \mathrm{~s}$. Attempts in those times were characterized by a search for so-called analytic solutions. Diameters and costs were taken into consideration with continuous value series. The diameters yielded were rounded to standard by diverse heuristic procedures. The "distance" between the standard diameters thus yielded and the real optimum was left unexplored [5-12].

Subsequent models were already characterized by best-first searches on sets of standard diameters using discrete diameter series and discrete cost functions. Extremum search was performed on discrete sets by various counting structures, such as the Branch and Bound method and dynamic programming [1,2].

Theoretically, dynamic programming proved to be a stable and convergent method. When applying this method, however, the rapidity of convergence and hitting the global optimum were failed to be analyzed. Bellmann's optimality principle is used in 
our practice of applying this method. The state variable to connect stages of decision making at nodes, that is, junction points of mains and branch-off conduits, is pressure difference between the forward and return conduits. Most frequent division thereof can make the solution even more accurate. Search for a solution can also be taken as a task of trying to find an optimal route [1,2].

This study presents a procedure based on dynamic programming, to guarantee convergence and finding the global optimum. The task is discussed with a systems theory and decision making theory approach; furthermore, efficiency of the method and error margins are discussed.

\section{Task specification}

Fig. 1 shows the topology image, structure and basic features of a district heating network. The network presented is radial, consisting of consumers, conduit sections connecting consumers, and a circulation system (pump). Conduit sections consist of a forward and a return conduit each. Conduit sections are separated by nodes. Basic geometric properties of conduit sections include conduit length and conduit diameter.

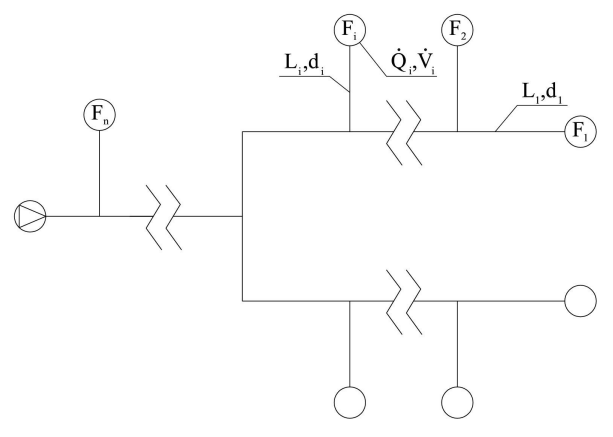

Fig. 1. District heating network: an illustration

Legend:

F consumer

$L \quad$ conduit length

d conduit diameter

$\dot{Q} \quad$ heat demand

$\dot{V} \quad$ hot water flow rate demand

Fig. 2 shows the graph of the district heating network in Fig. 1] A graph is a mathematical structure consisting of nodes and edges. The graph of a radial network is called a treestructured graph. This graph serves for the hydraulic, thermal engineering, and mathematical modelling of district heating network design and operation.

A graph-based modelling and optimization of district heating networks are presented by using so-called decision making systems. From a systems theory point of view, radial fixed-track district heating networks generally constitute diverging branch decision making systems (see Fig. 4] [3, 4]. The simplest district heating networks form a serial system. A decision making system shows inputs and outputs, decision making variables, the

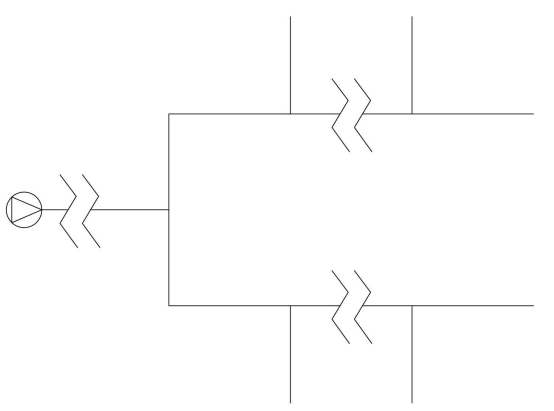

Fig. 2. Simplified model and graph of district heating network

transformation correlations linking them, and decision making results. The aim of decisions is to make decisions in function of the input and the required output of the system in order for the economic target function describing system operation to reach a minimum. Fig. 3 shows a model of a decision making system in a white box representation.

Dynamic programming is a mathematical method to optimize series of interdependent decisions [1]. The criterion for each decision in the series of decisions is to satisfy the optimality principle of dynamic programming. The original definition of the optimality principle states that: "An optimal decision making series is always characterized by the fact that whatever the initial state and the initial decision is, subsequent decision(s) constitute an optimal decision making series compared to the new state resulting from the first decision and the initial state" [1]. Decision making systems are broken down into stages of decision making (subsystems). According to the principle of optimality, decisions should be made by taking into consideration the options within the entire decision making process and should be optimal compared to the given state of the system. In the mathematical sense, our decisions satisfy a recursive function equation. The function equation of a serial system is as follows, using the notation of the general decision making process (Fig. 4):

$$
O\left(z_{m}\right)=\min _{u_{m}}\left\{f_{m}\left(z_{m}, u_{m}\right)+O\left(z_{m+1}\right)\right\} .
$$

And by introducing the state transformation to characterize given stage:

$$
O\left(z_{m}\right)=\min _{u_{m}}\left\{f_{m}\left(z_{m}, u_{m}\right)+O\left(g\left(z_{m}, u_{m}\right)\right)\right\} .
$$

By applying state transformation, the function equation will be a function of only the connection variable $\left(z_{m}\right)$ and the decision making variable $\left(u_{m}\right) . O\left(z_{m}\right)$ is the so-called optimal function, containing optimal decisions associated with decision making stages in respect of each value of the connection variable $z_{m}$.

\section{Optimization of serial decision making systems by dynamic programming}

Fig. 4 shows an abstract decision making model for serial systems. A decision making model is also termed as a white box 


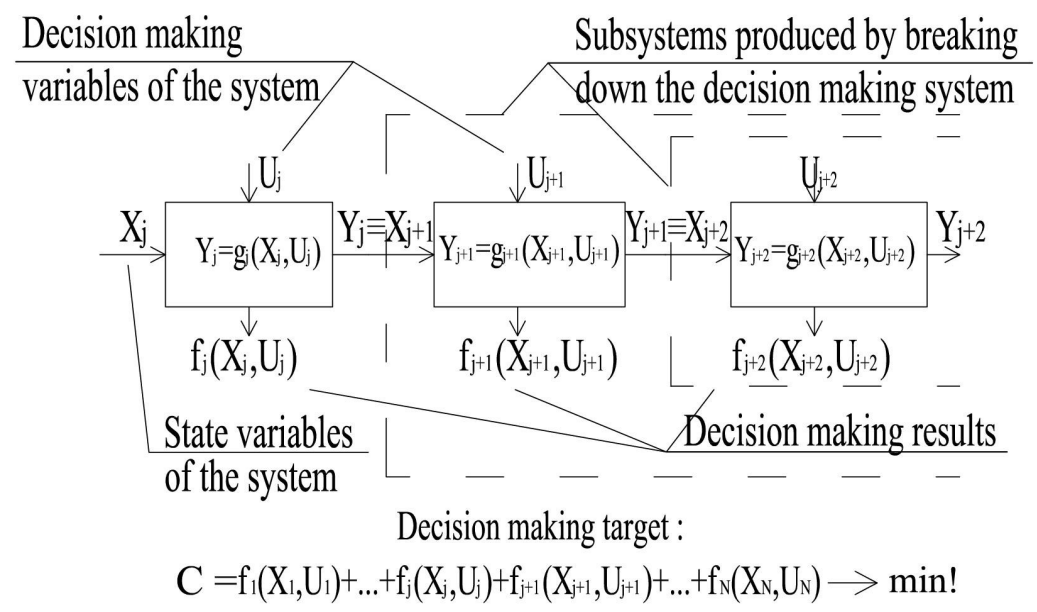

Fig. 3. Decision making system illustration

model. This model includes decision making variables $\left(u_{m}\right)$, decision making results $\left(f_{m}\right)$, and correlations between inputs and outputs (balance equations for the most part) $\left(g_{m}\right)$.

Optimization can be performed by backward or forward recursion. Recursive optimization backwards is most frequently applied as the system output - generally a consumer demand, e.g. heat demand - can be considered as given. In backward recursion, the function equation is solved recursively, from stage to stage, starting from the last stage, by a backward analysis of state transformations. This means that a set of optimal solutions - in respect of the totality of the stages examined - is generated for the given stage, in function of state variable $z_{m}$, by appropriate selection of the decision making variable $U_{m}$. The task is broken down into a series of subtasks by stating and solving the recursive function equation stage by stage.

\subsection{Optimization of serial systems by backward recursion} Target function:

$C=f_{1}+f_{2}+\ldots+f_{M}^{\prime}+f_{M+1}+f_{1}^{\prime}+\ldots+f_{L-1}^{\prime}+\ldots+f_{N-1}+f_{N} \rightarrow \min !$.

In fact, optimization is a conditional extremum calculation where conditional equations are represented by the transformation correlations written in the boxes. Independent variables include decision making variables, which - if appropriately selected - can minimize the target function.

\section{First step:}

To state the function equation starting from the last member.

$$
O\left(z_{n-1}\right)=\min _{U_{M}}\left\{f_{n-1}\left(z_{n-1}, u_{n-1}\right)+f_{n}\left(z_{n}\right)\right\}
$$

It holds true that:

$$
z_{n}=g_{n-1}\left(z_{n-1}, u_{n-1}\right) .
$$

The inverse of the function is used to express $u_{n-1}$,

$$
u_{n-1}=g_{n-1}^{-1}\left(z_{n-1}, z_{n}\right) .
$$

To be substituted Eq. (3), Eq. (4):

$$
O\left(z_{n-1}\right)=\left\{f_{n-1}\left[z_{n-1}, g_{n-1}^{-1}\left(z_{n-1}, z_{n}\right)\right]+f\left(z_{n}\right)\right\} .
$$

After this step, the optimum of our target function Eq. (3), Eq. (7) will only depend on the input and output variables. Nevertheless, $z_{n}$ is given in general as $z_{n}$ is the demand to be satisfied. There is no opportunity for optimization.

\section{Second step:}

The optimization equation is stated for the next box as well, to include the previous optimum function, too:

$$
O\left(z_{n-2}\right)=\min \left\{f_{n-2}\left(z_{n-2}, u_{n-2}\right)+O\left(z_{n-1}\right)\right\} .
$$

By using the equation in the box:

$$
z_{n-1}=g_{n-2}\left(z_{n-2}, u_{n-2}\right)
$$

Therefore:

$$
O\left(z_{n-2}\right)=\min _{u_{n-2}}\left\{f_{n-2}\left(z_{n-2}, u_{n-2}\right)+O\left(g_{n-2}\left(z_{n-2}, u_{n-2}\right)\right)\right\} .
$$

As our equation is minimized to the value of $u_{n-2}$, by substituting the optimum value of $u_{n-2}$ the only parameter to remain will be $z_{n-2}$. By continuing optimization, the value of $O_{m}$ is determined by the method presented above, to be followed by reaching the value $O_{1}$ to specify the optimum of the entire system. 


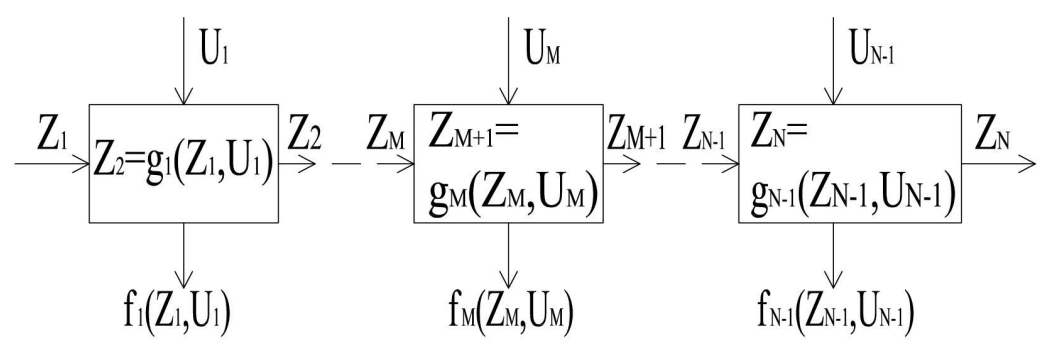

Decision making target :

$$
\mathrm{C}=\mathrm{f}_{1}+\mathrm{f}_{2}+\ldots+\mathrm{f}_{\mathrm{M}}+\ldots+\mathrm{f}_{\mathrm{N}} \rightarrow \min !
$$

Fig. 4. Decision making model of a serial system

A serial connection can also be effected by forward recursion. By using this recursion, $u_{1}$ can be eliminated, but $z_{1}$, and $z_{2}$ will remain. If the value of $z_{1}$ is known, it can be omitted after the first step; if it is unknown, it will figure in our functions as an unknown all throughout the optimization process.

\subsection{Diverging branch system investigation}

Fig. 5 shows the basic model for analyzing a diverging branch system.

Target function:

$$
C=f_{1}+f_{2}+\ldots+f_{1}^{\prime}+\ldots+f_{L-1}^{\prime}+\ldots+f_{N-1}+\ldots+f_{N} \rightarrow \min !
$$

When examining diverging branch systems (Fig. 5), those steps of the optimization process are presented when the task derogates from what is described in the case of serial systems. The equations stated for the optimization of serial systems are applied for diverging branch systems. The connection stage is reached along the branches by backward recursion. The problem is the connection stage. The following equations can be stated for the connection stage:

$$
O\left(z_{M}\right)=\min _{U_{M}}\left\{f_{m}\left(z_{m}, u_{m}\right)+O_{1}^{\prime}\left(z_{1}^{\prime}\right)+O_{m+1}\left(z_{m+1}\right)\right\}
$$

After substituting the transformation equations:

$$
\begin{aligned}
O\left(z_{M}\right)= & \min _{U_{M}}\left[f_{M}\left(Z_{M}, U_{M}\right)+O_{1}^{\prime}\left(g_{M}^{\prime}\left(Z_{M}, U_{M}\right)\right)+\right. \\
& \left.+O_{M+1}\left(g_{M+1}\left(Z_{M}, U_{M}\right)\right)\right]
\end{aligned}
$$

After determining $O\left(z_{m}\right)$, progress is made along the main branch until reaching stage one. And at stage one, the optimization function of the entire diverging branch system is yielded.

\section{Optimization of district heating networks by dynamic programming}

In a white box representation, radial pipe networks constitute a complex diverging branch system of decision making from the systems theory point of view; theoretical optimization thereof was presented in Chapter 3.

Fig. 6 shows a decision making system for the optimization of radial pipe networks in a white box layout.

- The decision making variables $\left(d_{j_{k}}\right.$ and $\left.d_{j_{k}}^{\prime}\right)$ of system elements, of each "stage", are sets of standard diameters assigned to the pipe section symbolized by the white box (therefore eligible).

- Decision making results $\left(f_{j_{k}}, f_{j_{k}}^{\prime}\right.$ and $\left.f_{j_{k}}^{*}\right)$ represent the costs incurred in the given stage (along the pipe section concerned) by applying standard diameters.

- Costs of type $f_{j_{k}}$ include the total costs of pumping $\left(K_{1 j_{k}}\right)$, investment $\left(K_{2 j_{k}}\right)$ and heat loss $\left(K_{3 j_{k}}\right)$ along the section concerned during the lifetime of the network, by applying a standard diameter, discounted, in a comparable format. Therefore:

$$
f_{j_{k}}=K_{1 j_{k}}\left(d_{j_{k}}\right)+K_{2 j_{k}}\left(d_{j_{k}}\right)+K_{3 j_{k}}\left(d_{j_{k}}\right)
$$

$$
f_{j_{k}}=\sum_{t} \frac{\dot{V}_{j_{k}} \Delta p_{j_{k}}}{\eta} \tau_{\ddot{u}, j_{k}, t} f_{E} a_{j_{k}, t}+K_{2 j_{k}}\left(d_{j_{k}}\right)+K_{3 j_{k}}\left(d_{j_{k}}\right),
$$

- $f_{j_{k}}^{\prime}$ is the same as $f_{j_{k}}$, only with $d_{j_{k}}^{\prime}$.

- Costs of type $f_{j_{k}}^{*}$ include the costs of extra pumping to arise by stemming as required for establishing the fluid flows as demanded in the course of system adjustment. The white box represents a node at the junction of branches. 


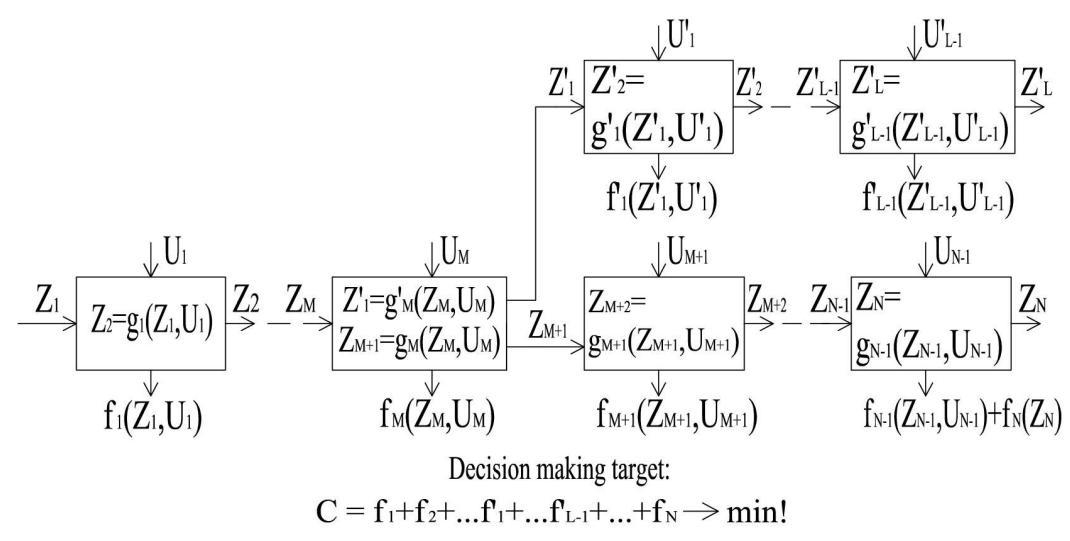

Fig. 5. Decision making model of a serial system

$$
f_{j_{k}}^{*}=\left(h_{j_{k}}^{*}-h_{j_{k}}^{\prime}\right) \dot{V}_{j_{k}}^{\prime} \frac{\tau_{\ddot{u}, j_{k}} f_{E}}{\eta} .
$$

In the formulas:

Legend:

$\dot{V}_{j_{k}} \quad$ flow rate,

$\Delta p_{j_{k}} \quad$ pressure loss,

$\tau_{\ddot{i}, j_{k}} \quad$ uptime,

$f_{E} \quad$ unit cost of electric power,

$\eta \quad$ pumping efficiency.

- Pressure values are prescribed at the end of each branch:

$$
\Delta p_{j_{k}, 0}^{\prime}=\text { constant }
$$

- Pressure values at each node may not exceed the limits prescribed:

$$
h_{j_{k}}^{*} \leq R_{j_{k}} .
$$

The total cost of the pipe network is obviously the aggregate of the costs of sections. Therefore the network optimality criterion is:

$$
\begin{aligned}
& f=f_{N_{2}}+f_{N_{2}}^{\prime}+f_{N_{2}}^{*}+f_{N_{2}-1}+f_{N_{2}-1}^{\prime}+f_{N_{2}-1}^{*}+\ldots+ \\
& +f_{j_{k}}+f_{j_{k}}^{\prime}+f_{j_{k}}^{*}+\ldots+f_{l_{1}}+f_{l_{1}}^{\prime}+f_{l_{1}}^{*} \rightarrow \min .
\end{aligned}
$$

Appropriate recursive function equations are constructed in order to optimize the system.

Node pressures $h_{j_{k}}^{*}$ are selected as connection variables of system elements. Thereby

$$
\begin{aligned}
O\left(h_{j_{k}}^{*}\right)= & \min _{d_{j k}}\left[f_{j_{k}}\left(d_{j_{k}}\right)+f_{j_{k}}^{*}\left(h_{j_{k}}^{*}, h_{j_{k}}, h_{j_{k}}^{\prime}\right)+\right. \\
& \left.+O_{j_{k}}^{\prime}\left(h_{j_{k}}^{\prime}\right)+O\left(h_{j_{k}+1}^{*}\right)\right] .
\end{aligned}
$$

Correlations between connection variables - that is, state transformations - are as follows:

$$
h_{j_{k}}^{\prime} \leq h_{j_{k}}^{*}
$$

$$
h_{j_{k}}=. h_{j_{k+1}}^{*}+\Delta p_{j_{k}} \leq h_{j_{k}}^{*} .
$$

State transformations are used to establish connections between node pressures. Consumer demands can be satisfied, branch flows can be adjusted only by stemming some of the branches in general. Node pressure is determined by pressure drop either in the consumer branch or the mains, depending on which is the higher. In order to transfer the required flow, the branch of less resistance must be stemmed. This is expressed by relations (18) and (22), according to which pressure at a node may not be less than the value of the preceding node pressure increased by pressure loss along the section connecting the two nodes.

The decision making system shown in Fig. 6 provides information about both decisions on the optimal diameters of the network and network adjustment. The decision making system in Fig. 7 was constructed to model decisions on network optimization in the strict sense only. Costs of additional pumping due to model network adjustment are taken into consideration at the resulting input pressure since the total pumping work of the pipe network is known to be a unique, monotonically increasing function of the input pressure. Thus, pumping costs can be associated with the cost of the first element (box) in the decision making system, as a function of the input pressure. Thereby the cost of the first system element will be:

$$
f_{l_{1}}^{*}=\frac{\dot{V}_{l_{1}} h_{l_{1}}^{*} \tau_{\ddot{u}}}{\eta} f_{E} .
$$


And the cost of the rest of the system elements will be:

$$
f_{j_{k}}=K_{2, j_{k}}\left(d_{j_{k}}\right)+K_{3, j_{k}}\left(d_{j_{k}}\right) \text {, }
$$

Pumping work calculated by the input pressure a priori also includes the costs of additional pumping due to system adjustment; accordingly:

$$
f_{j_{k}}^{*}=0 .
$$

The recursive function equation expressing the optimality principle can be stated as follows:

$$
O_{j_{k}}\left(h_{j_{k}}^{*}\right)=\min _{d_{j k}}\left[f_{j_{k}}\left(d_{j_{k}}\right)+O_{j_{k+1}}\left(h_{j_{k+1}}^{*}\right)+O_{j_{k}}^{\prime}\left(h_{j_{k}}^{\prime}\right)\right] .
$$

Correlations between connection variables do not change, therefore:

$$
\begin{aligned}
& h_{j_{k}}^{\prime} \leq h_{j_{k}}^{*}, \\
& h_{j_{k+1}}^{*}+\Delta p_{j_{k}} \leq h_{j_{k}}^{*} .
\end{aligned}
$$

In decision making system optimization, node pressures (pressure differences) $h_{j_{k}}^{*}$ are taken as a series of discrete values located sufficiently densely. In the current stage of optimization, network parts $O_{j_{k}}\left(h_{j_{k}}^{*}\right)$ of minimal cost are produced in function of the discrete values of node pressure $h_{j_{k}}^{*}$, by an appropriate selection of an optional standard diameter $d_{j_{k}}^{*}$ which complies with the speed limits prescribed. When solving the function equation, costs of the network section up to stage $j k$ are minimized by selecting values which, in the aggregate, yield a minimum figure, from the discrete empirical costs of the network section up to the (already optimized) stage $j_{k+1}$ (parametrically, in function of the discreet values of node pressure $h_{j_{k+1}}^{*}$ ), and those of the standard diameters $d_{j_{k}}$ and $d_{j_{k}}^{\prime}$ of stage $j_{k}$, reflecting all circumstances related to topology and laying.

Pipe networks can be optimized either by fixing or not fixing the input pressure (perhaps only by using an upper boundary to limit the input pressure). It does not constitute a theoretical and substantial methodological restriction for discrete dynamic programming if the value of the input pressure is prescribed.

At this point, in the first stage of the decision making system (and the last one in the sequence of optimization operations), the determination of pumping work is disregarded in cost calculations. From the discrete value series of input pressure $h_{l_{1}}^{*}$, constituting the input of this stage (as a parameter), the one coinciding with the prescribed input pressure is selected (such discrete value series can be compiled arbitrarily), and the last stage is optimized - the cost function $O\left(h_{l_{1}}^{*}\right)$ is minimized only for this single value $\left(h_{l_{1}}^{*}=\right.$ const. $)$.

In the event that no input pressure is strictly prescribed, pumping costs are assigned to the first element of the decision making system in function of input pressure $h_{l_{1}}^{*}$, constituting the input to the first "box" (considered as a variable). After solving the function equation stated on the first "box", the optimal input pressure is also determined by comparing the optimal costs $O\left(h_{l_{1}}^{*}\right)$ and by selecting the minimum cost.

It is conspicuous that in the successive solutions of the recursive function equation, all technical and economic requirements can be fully satisfied, and the topology, hydraulics and cost conditions of the network can be precisely analyzed simultaneously with optimization.

The success of optimization depends on increasing the breakdown frequency of pressure differences at nodes. Fig. 8 provides a model for latticing pressure differences at nodes according to classic optimization, taking a simple network as an example (Fig.9).

A minimum and a maximum diameter can be taken into consideration for each conduit section, with the optimal diameter expected to be somewhere in between. The upper and lower boundaries of the pressure figure are specified by the pressure losses calculated by using the minimum and maximum diameters, as shown in the figure. Latticing the nodes of the pressure figure will yield a graph on which the task of searching for the optimal route can be defined. The problem is the frequency of node selection within the graph. The following model can be applied for the size of the error possible to be committed. The optimum of the cost function should be estimated. Then a so-called unconditional optimization of the network should be performed, defining independently the standard conduit diameter for each conduit section where the investment cost, heat loss cost and flow cost of the section are minimal in the aggregate.

Then the pressure image of the network should be constructed and costs should be added up according to Fig. 9

In order to equalize pressures, stemming must be performed at the node in consumer branch-offs to adjust the required flow rates. Such stemming actions increase pumping costs. Curve (A) shows network costs, while curve (B) shows increased resultant costs arising from additional pumping due to stemming.

The optimum to be found in the set of standard pipe diameters cannot be smaller than the value of curve (A); and the exact optimum can be located between curves (A) and (B) if it exists at all. Let us try to find a solution between curves (A) and (B) Optimization should be performed using the optimal diameters defined according to independent optimums and their neighbours, by applying Bellmann's optimality principle and dynamic programming: to understand it more easily, on a serial system model similar to Fig. 7) (see Fig. 8)

Let the standard diameters to be taken into consideration for conduit sections (1) and (2) be as follows:

$$
\left\{d_{(1), 1}, d_{(1), o p t}, d_{(1), 3}\right\},\left\{d_{(2), 1}, d_{(2), o p t}, d_{(2), 3}\right\}
$$

So-called recursive optimization functions should be generated by tagging assigned to section (2) as follows:

$$
O_{(2) 1}\left(d_{(2) 1}\right)=\left\{K_{(2) 1}\left(d_{(2) 1}\right)+K_{(1) i}\left(d_{(1) i}\right)\right\}
$$




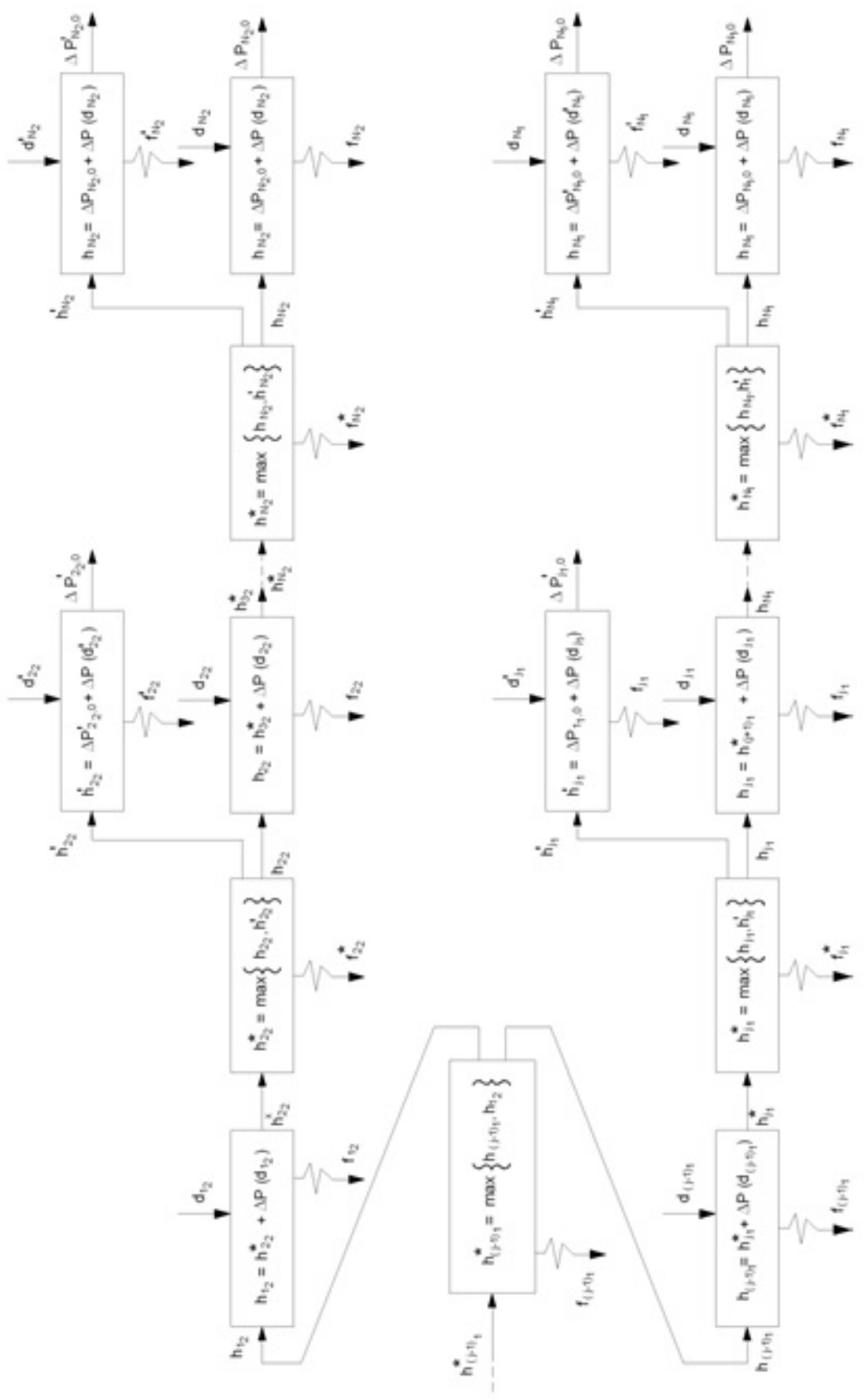

Fig. 6. Decision making model of a diverging branch system 


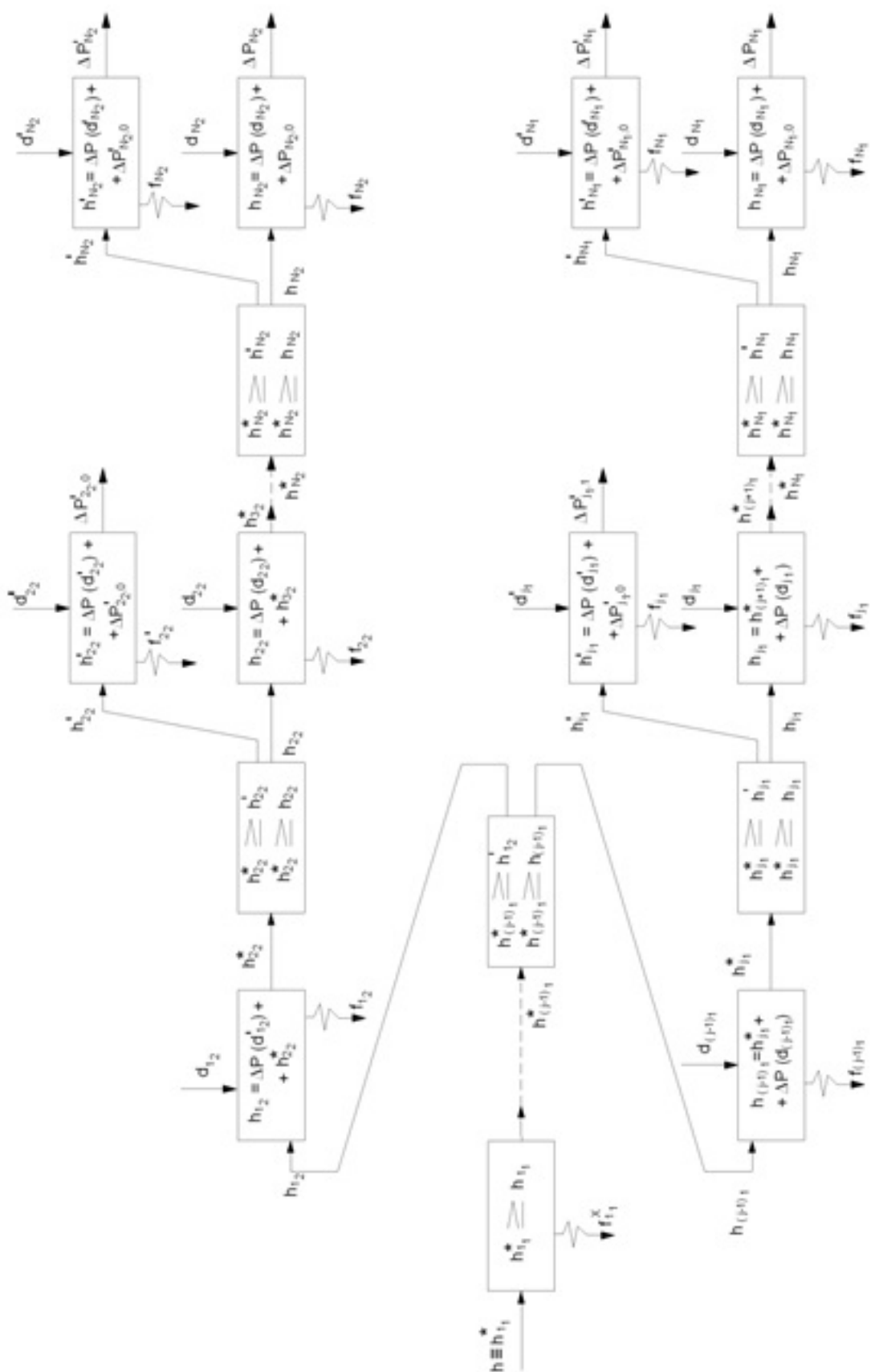

Fig. 7. Decision making model for the optimization of radial fixed-track pipe networks as a diverging branch system of decision making 


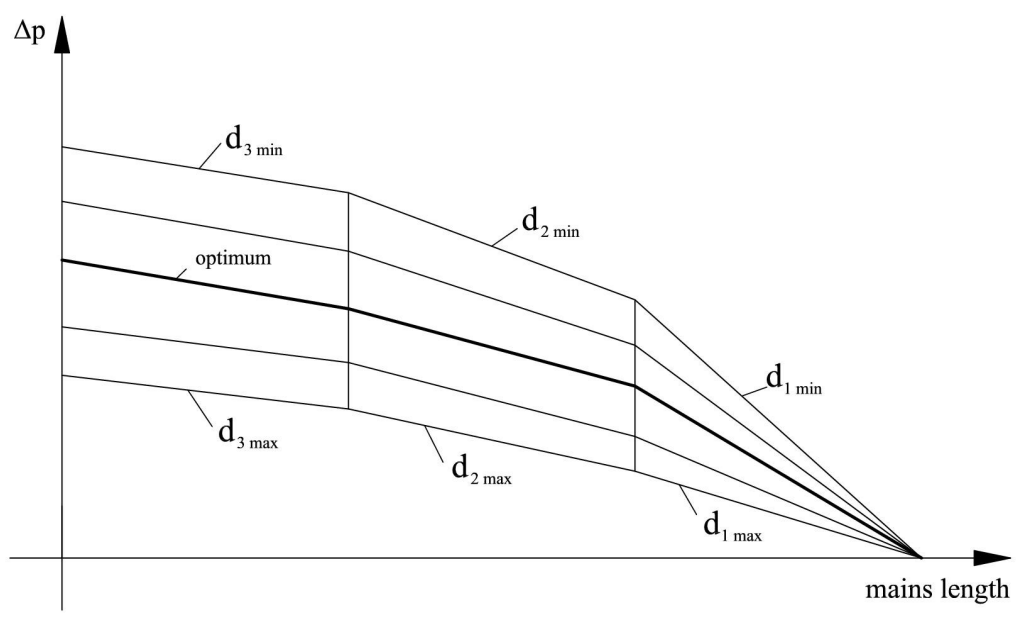

Fig. 8. Lattice model of pressure differences at nodes

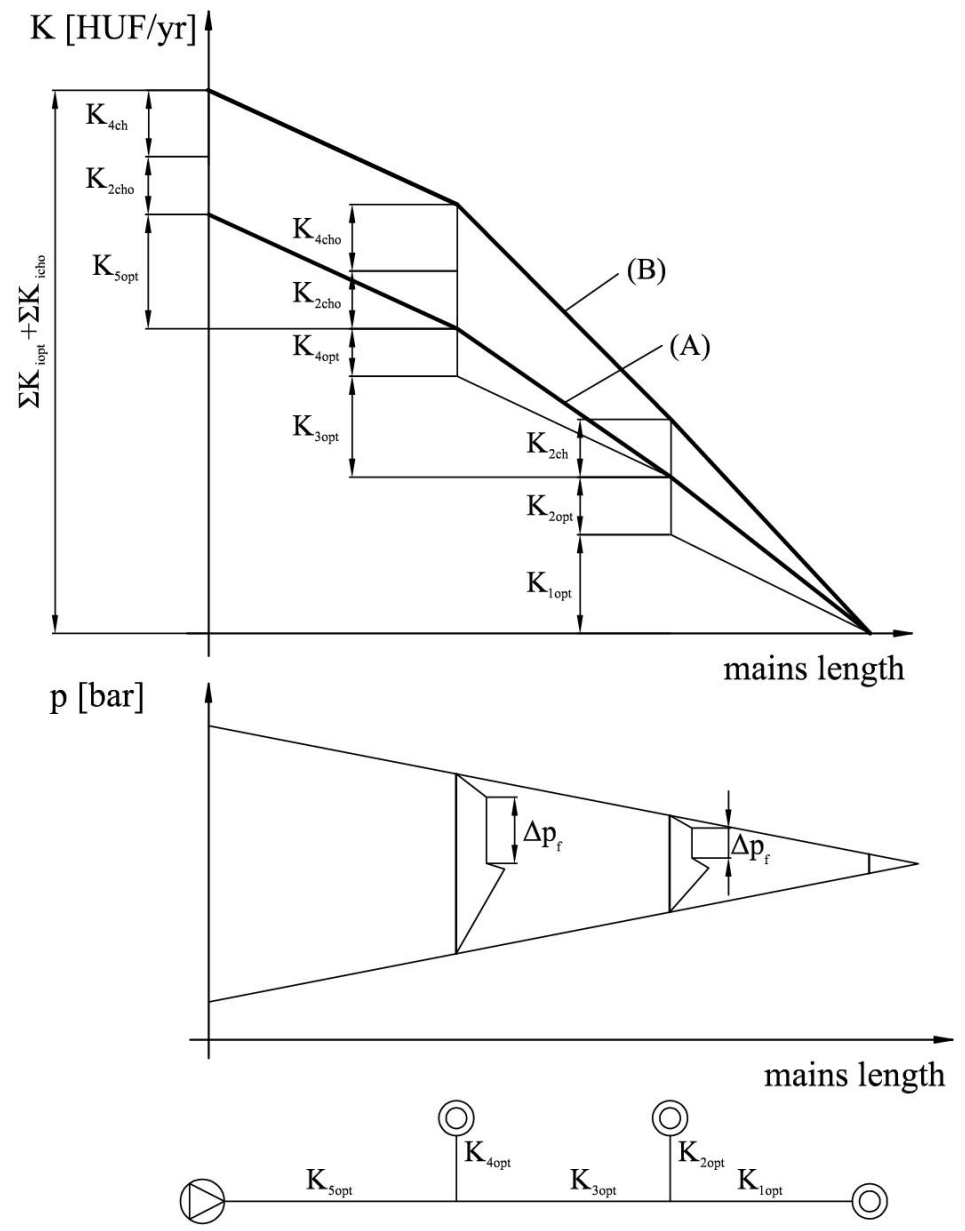

Fig. 9. Pressure and cost figure of the network by system-independent optimization 


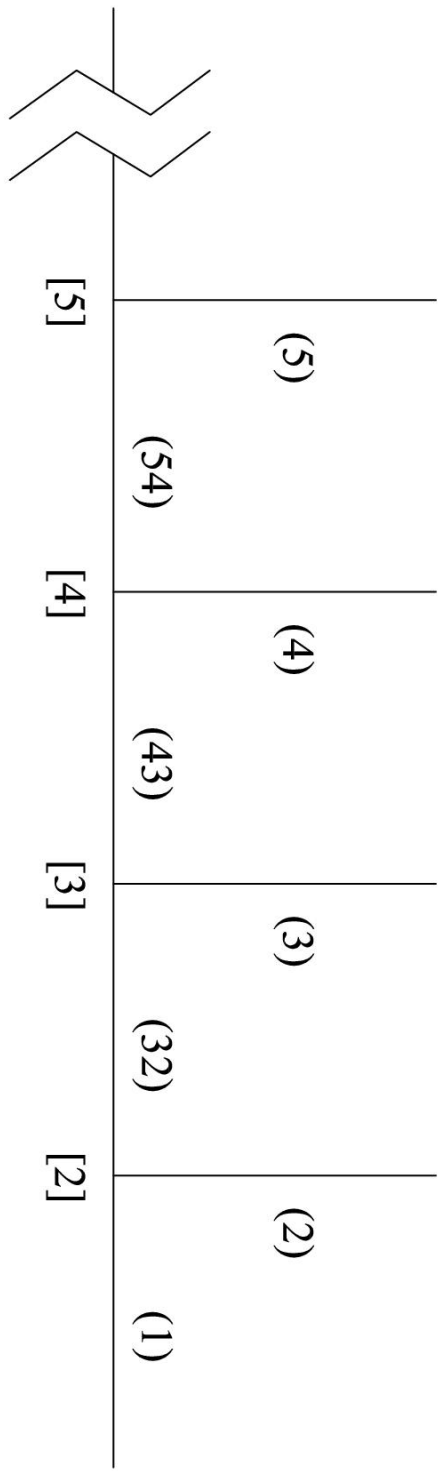

Fig. 10. Network model for best-first search and positioning between curves (A) and (B) 


$$
\begin{aligned}
& O_{(2) 2}\left(d_{(2) 2}\right)=\left\{K_{(2) 2}\left(d_{(2) 2}\right)+K_{(1) i}\left(d_{(1) i}\right)\right\} \\
& O_{(2) 3}\left(d_{(2) 3}\right)=\left\{K_{(2) 3}\left(d_{(2) 3}\right)+K_{(1) i}\left(d_{(1) i}\right)\right\}
\end{aligned}
$$

where:

$$
i=1,2,3
$$

Recursive optimality functions should be generated by tagging assigned to section (3), using the partial optimums $\mathrm{O}_{2}$ previously yielded as follows:

$$
\begin{aligned}
& O_{(3) 1}\left(d_{(3) 1}\right)=\left\{K_{(32) j}\left(d_{(32) j}\right)+K_{(3) 1}\left(d_{(3) 1}\right)+O_{(2) i}\left(d_{(2) i}\right)\right\} \\
& O_{(3) 2}\left(d_{(3) 2)}\right)=\left\{K_{(32) j}\left(d_{(32) j}\right)+K_{(3) 2}\left(d_{(3) 1}\right)+O_{(2) i}\left(d_{(2) i}\right)\right\} \\
& O_{(3) 3}\left(d_{(3) 3}\right)=\left\{K_{(32) j}\left(d_{(32) j}\right)+K_{(3) 3}\left(d_{(3) 3}\right)+O_{(2) i}\left(d_{(2) i}\right)\right\}
\end{aligned}
$$

where:

$$
i=1,2,3 \quad j=1,2,3
$$

The procedure is continued in a recursive fashion and optimal functions are stored in the meantime. In each stage of decision making, an optimal diameter structure is associated with three possible branch-off diameters. In each stage of decision making, $3 \times 3=9$ cost variants should be compared in respect of each tag. When reaching the pump, optimization is performed for the last 3 tags. The previous optimal tag is associated with each tag, and both the optimal diameters and the optimal pressure image can be called in by moving backwards. If the cost function yielded does not proceed below curve (B), then there is no network with better costs than the concatenation of system-independent optimums.

Example: Specify the optimum diameters of the radial hot water district heating network shown in the figure attached by the approximation procedure presented in this chapter and by an optimization method based on dynamic programming.

Note: The length of connecting conduits supplying consumers F3, F13, F14, F15, F16, and F17 can be neglected because of their shortness.

The district heating network operates with a temperature step of $110 / 55^{\circ} \mathrm{C}$; consumer and section data are included in Table 1 and Table 2

Table 3 shows specific investment costs for standard pipe diameters:

\begin{tabular}{|c|c|}
\hline Section name & Length [m] \\
\hline 1 & 440 \\
\hline 11 & 14 \\
\hline 2 & 125 \\
\hline 21 & 24 \\
\hline 22 & 54 \\
\hline 3 & 67 \\
\hline 31 & 6 \\
\hline 4 & 54 \\
\hline 41 & 73 \\
\hline 42 & 77 \\
\hline 43 & 100 \\
\hline 5 & 71 \\
\hline 51 & 51 \\
\hline 6 & 184 \\
\hline 61 & 26 \\
\hline 62 & 83 \\
\hline 63 & 74 \\
\hline 64 & 4 \\
\hline 7 & 84 \\
\hline 71 & 99 \\
\hline 72 & 27 \\
\hline 73 & 25 \\
\hline 74 & 50 \\
\hline 75 & 40 \\
\hline 76 & 50 \\
\hline 77 & 20 \\
\hline 8 & 42 \\
\hline 81 & 100 \\
\hline 9 & 160 \\
\hline
\end{tabular}

The HUF/ running metre of track values used for investment cost calculations are average values calculated on the basis of recent years' conduit construction experience.
Tab. 1. Data on radial hot water district heating network

\begin{tabular}{cc}
\hline Consumer & Heat demand [kW] \\
\hline$F 1$ & 1,300 \\
\hline$F 2$ & 662 \\
\hline$F 3$ & 225 \\
\hline$F 4$ & 762 \\
\hline$F 5$ & 270 \\
\hline$F 6$ & 360 \\
\hline$F 7$ & 66 \\
\hline$F 8$ & 540 \\
\hline$F 11$ & 2,075 \\
\hline$F 10$ & 1,010 \\
\hline$F 9$ & 1,355 \\
\hline$F 12$ & 1,998 \\
\hline$F 18$ & 240 \\
\hline$F 17$ & 240 \\
\hline$F 16$ & 240 \\
\hline$F 15$ & 240 \\
\hline$F 14$ & 240 \\
\hline$F 13$ & 240 \\
\hline$F 19$ & 156 \\
\hline
\end{tabular}

Tab. 2. Data on radial hot water district heating network 


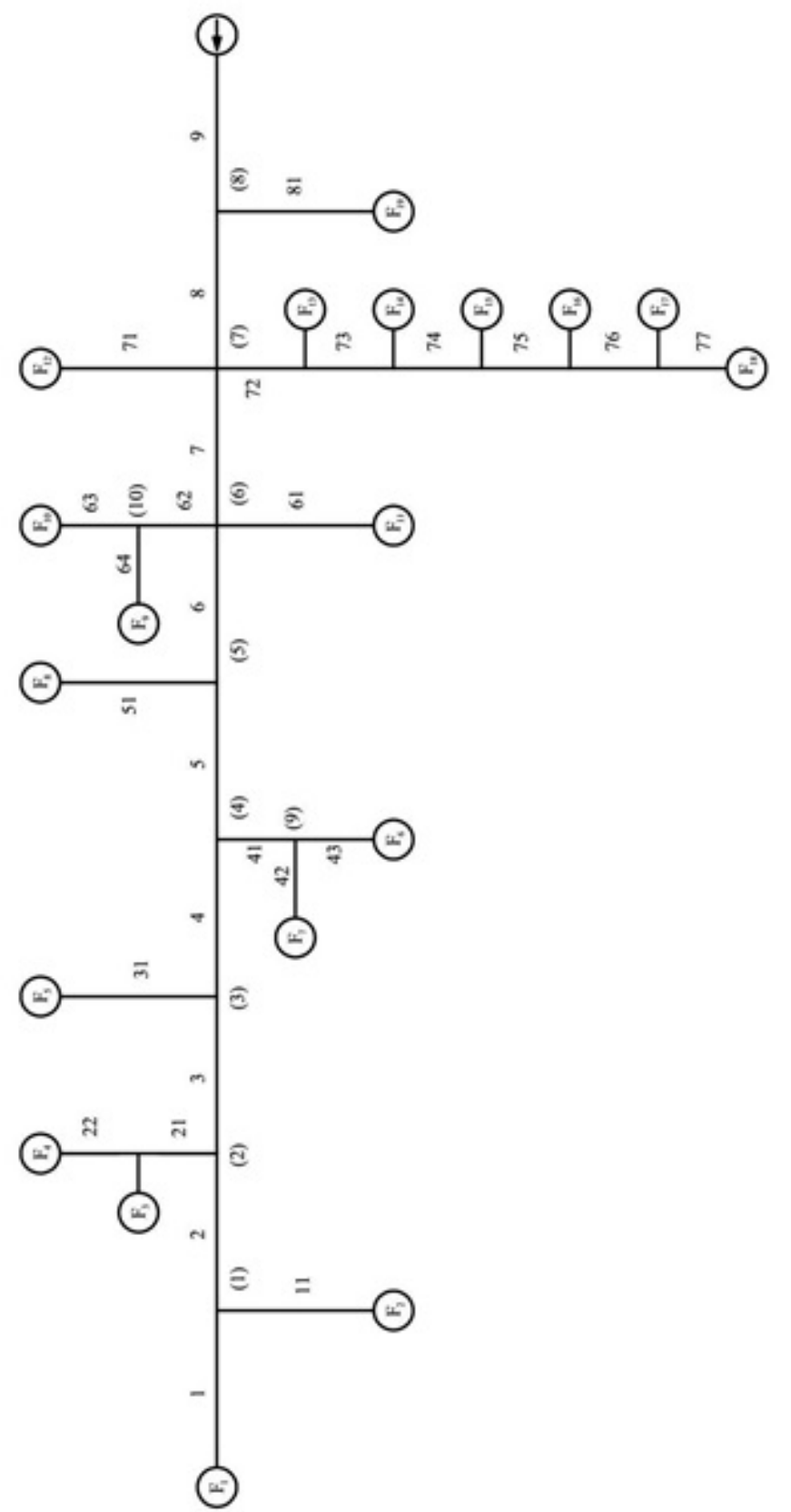

Fig. 11. Model of radial district heating network 
Tab. 3. Specific investment costs

\begin{tabular}{cc}
\hline Pipe diameter & HUF/ running metre of track \\
\hline DN25 & 38,000 \\
\hline DN32 & 45,000 \\
\hline DN40 & 48,000 \\
\hline DN50 & 52,000 \\
\hline DN65 & 62,000 \\
\hline DN80 & 70,000 \\
\hline DN100 & 80,000 \\
\hline DN125 & 95,000 \\
\hline DN150 & 110,000 \\
\hline DN200 & 140,000 \\
\hline DN250 & 170,000 \\
\hline DN300 & 205,000 \\
\hline DN350 & 230,000 \\
\hline
\end{tabular}

Tab. 4. Pipe diameters calculated by system-independent and system-based optimization

\begin{tabular}{|c|c|c|}
\hline Section name & $\begin{array}{c}\text { Pipe diameters } \\
\text { calculated by } \\
\text { system-independent } \\
\text { optimization }\end{array}$ & $\begin{array}{c}\text { Pipe diameters } \\
\text { calculated by } \\
\text { system-based } \\
\text { optimization }\end{array}$ \\
\hline 1 & DN100 & DN100 \\
\hline 11 & DN65 & DN50 \\
\hline 22 & DN40 & DN40 \\
\hline 2 & DN100 & DN100 \\
\hline 21 & DN80 & DN65 \\
\hline 3 & DN125 & DN125 \\
\hline 31 & DN50 & DN32 \\
\hline 4 & DN150 & DN150 \\
\hline 43 & DN50 & DN50 \\
\hline 42 & DN25 & DN25 \\
\hline 41 & DN50 & DN50 \\
\hline 5 & DN150 & DN150 \\
\hline 51 & DN65 & DN50 \\
\hline 6 & DN150 & DN150 \\
\hline 61 & DN125 & DN100 \\
\hline 63 & DN80 & DN80 \\
\hline 64 & DN100 & DN80 \\
\hline 62 & DN125 & DN100 \\
\hline 7 & DN250 & DN250 \\
\hline 71 & DN125 & DN125 \\
\hline 77 & DN40 & DN40 \\
\hline 76 & DN50 & DN50 \\
\hline 75 & DN65 & DN50 \\
\hline 74 & DN80 & DN65 \\
\hline 73 & DN100 & DN80 \\
\hline 72 & DN100 & DN100 \\
\hline 8 & DN250 & DN250 \\
\hline 81 & DN32 & DN32 \\
\hline 9 & DN250 & DN250 \\
\hline
\end{tabular}

The first step is to specify a so-called system-independent optimum for each conduit section, that is, the minimum aggregate cost of conduit section investment and hot water circulation. In order to be able to determine the optimal conduit diameter, annual operating costs and the write-off of annual investment costs should be known. The minimum of the aggregate of these two curves will determine the optimal standard diameter value for the section concerned.

By way of an example, the system-independent optimum of the conduit section supplying consumer F5 is determined (Fig. 12).

The diagram clearly shows the minimum value of the function at $0.05 \mathrm{~m}$; pipe diameter DN50 associated with that value will ensure an optimal total cost.

After calculations by system-based optimization on the network illustrated, it can be established that the annual total cost of the system has been reduced by $4 \%$ compared to dimensioning by system-independent optimization (Table 5 .

The pressure diagram of the network is presented in Fig. 13 and the costs on the main run of the investigated network are shown in Fig. 14 .

\section{Conclusions}

Specification of optimal pipe diameters for district heating systems involves the selection of a conduit diameter for each section of the district heating system whereby the annual proportion of the investment cost of the network, the annual direct cost of operation, as well as the aggregate cost of hot water circulation and heat loss are minimized.

An efficient solution for this problem, effective from the engineering point of view and of substantial practical value, is still missing. This paper presented a procedure based on dynamic programming, to guarantee convergence and finding the global optimum. The task is discussed with a systems theory and decision making theory approach. Calculations were performed for fifty hungarian district heating networks. Compared to the common design method our optimalization method resulted in

Tab. 5. Comparison of system-independent and system-based optimization

\begin{tabular}{lccc}
\hline Nodes & $\begin{array}{c}\text { Aggregate cost } \\
\text { of system- } \\
\text {-independent } \\
\text { optimization } \\
\text { [HUF thou / yr] }\end{array}$ & $\begin{array}{c}\text { System- } \\
\text { independent } \\
\text { optimization }+ \\
\text { stemming cost } \\
\text { [HUF thou / yr] }\end{array}$ & $\begin{array}{c}\text { System- } \\
\text { based } \\
\text { optimization + } \\
\text { stemming cost } \\
\text { [HUF thou / yr] }\end{array}$ \\
\hline pump & $9,140.17$ & $10,954.59$ & $10,485.32$ \\
\hline$(8)$ & $7,784.07$ & $9,598.48$ & $9,129.21$ \\
\hline$(7)$ & $7,233.57$ & $9,028.90$ & $8,559.63$ \\
\hline$(6)$ & $5,586.59$ & $6,795.18$ & $6,678.29$ \\
\hline$(5)$ & $3,888.42$ & $4,192.09$ & $4,142.20$ \\
\hline$(4)$ & $3,394.77$ & $3,610.58$ & $3,583.17$ \\
\hline$(3)$ & $2,608.11$ & $2,801.95$ & $2,774.55$ \\
\hline$(2)$ & $2,281.25$ & $2,433.02$ & $2,410.14$ \\
\hline$(1)$ & $1,556.71$ & $1,608.15$ & $1,602.55$ \\
\hline
\end{tabular}




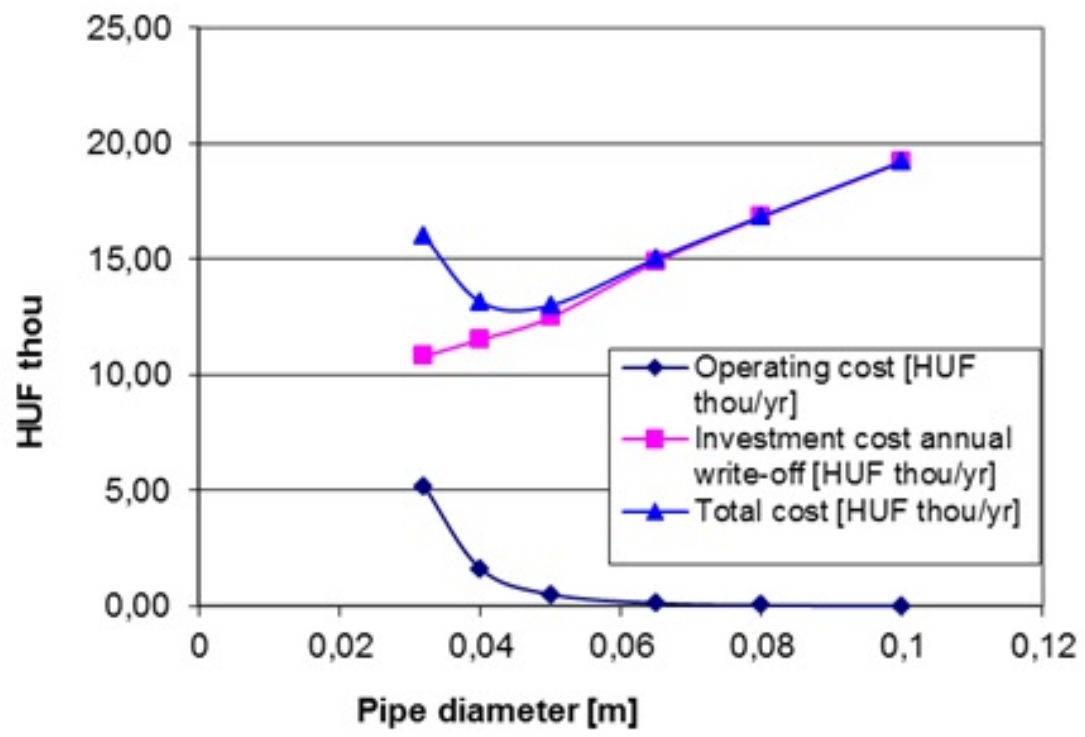

Fig. 12. Investment and operating costs of the conduit section supplying consumer F5

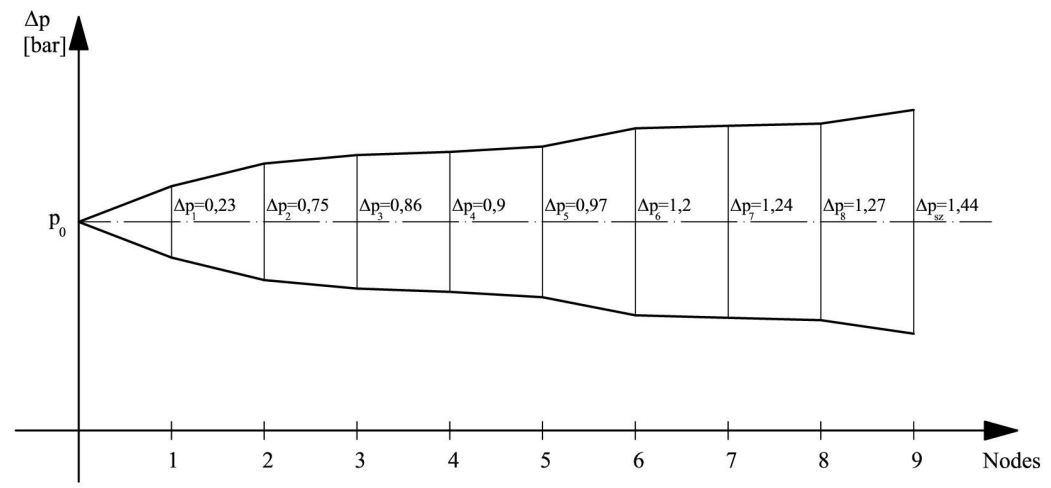

Fig. 13. Pressure diagram of the district heating network examined

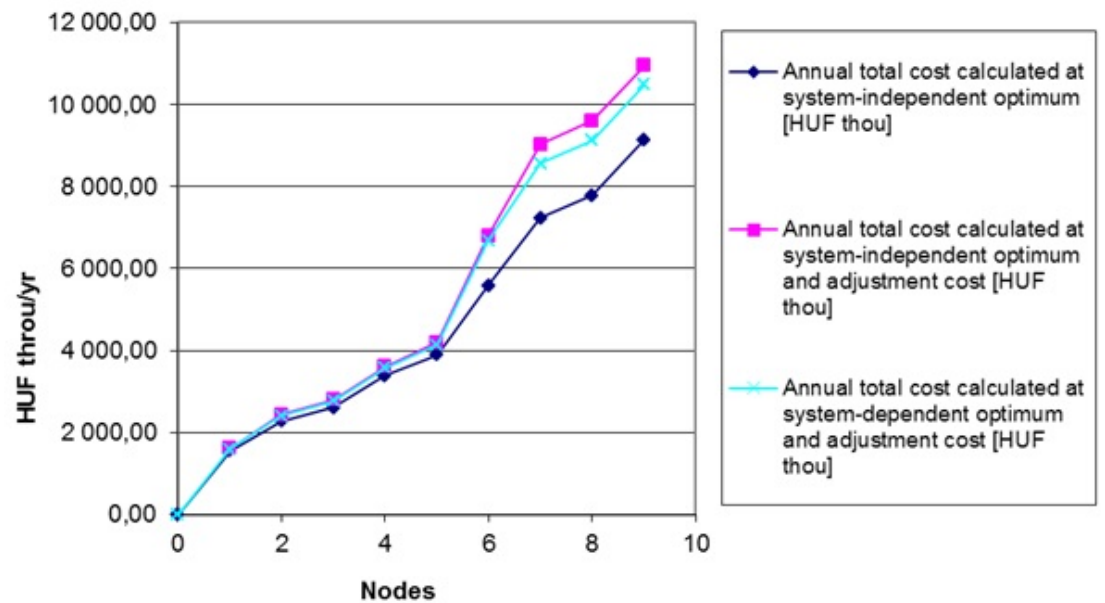

Fig. 14. Pressure diagram of the district heating network examined 
$4-5 \%$ cost saving. This improved variant of the dynamic programing described in the present paper have multiplied the speed of the calculation. With optimums independent of the system its possible to estimate the exact boundaries between which the optimum lies. This is the most important result of our paper as no constraints were determined by other researchers before. We have also proven that less calculation capacity is needed with the labeling method.

\section{References}

1 Garbai L, Dezső Gy, Flow in Building Engineering Conduit Systems (in hungarian), Múszaki Könyvkiadó, 1986.

2 Belmann R E, Dynamic Programing, Princeton University Press, 1962.

3 Aris R, Nemhauser G L, Wilde D J, Optimization of multistage cyclic and branching systems by serial procedures, AIChE Journal, 10(6), (1964), 913919, DOI 10.1002/aic.690100626

4 Garbai L, District Heating (in hungarian), Typotex Kiadó, 2012.

5 Phetteplace G, Optimal Design of Piping Systems for District Heating, 1995.

6 Xiang-li L, Duanmun L, Hai-wen S, Optimal design of district heating and cooling pipe network of seawater-source heat pump, Energy and Buildings, 42(1), (2010), 100-104, DOI 10.1016/j.enbuild.2009.07.016

7 Jamsek M, Dobersek D, Goricanec D, Krope J, Determination of Optimal District Heating Pipe Network Configuration, WSEAS Transactions on Fluid Mechanics, 5(3), (2010), 165-174.

8 Tol H I, Svendsen S, Improving the dimensioning of piping networks and network layouts in low-energy district heating systems connected to lowenergy buildings: A case study in Roskilde, Denmark, Energy, 38(1), (2012), 276-290, DOI 10.1016/j.energy.2011.12.002

9 Hlebniko A, Dementjeva N, Siirde A, Optimization of Narva District Heating Network and Analysis of Competitiveness of Oil Shale CHP Building in Narva, Oil Shale, 26(3), (2009), 269-282, DOI 10.3176/oil.2009.3S.09

10 Afsjar M H, Afshar A, Marino M A, Hon M, An Iterative Penalty Method for the Optimal Design of Pipe Networks, Internation Journal of Civil Engineering, 7(2), (2009), 109-123.

11 Wang W, Cheng X, Liang X, Optimization modeling of district heating networks and calculation by the Newton method, Applied Thermal Engineering, 61(2), (2013), 163-170, DOI 10.1016/j.applthermaleng.2013.07.025

12 Sakawa M, Matsui T, Fuzzy multiobjective nonlinear operation planning in district heating and cooling plants, Fuzzy Sets and Systems, 231, (2013), 58-69, DOI $10.1016 / j$.fss.2011.10.020 